Canadian Oncology

Nursing Journal

Revue canadienne

de soins infirmiers

en oncologie

Volume 28, Issue 2 • Spring 2018

elSSN: 2368-8076 


\section{Partnership between patients, nurse leaders and researchers: Outcomes of a web-based KT strategy for hospital discharge planning and care transitions in oncology}

by Hélène Lefebvre, Isabelle Brault, Odette Roy, Marie-Josée Levert, Dan Lecocq, Maryse Larrivière, Michelle Proulx, in collaboration with André Myre, André Néron Caroline Plante, Claudine Tremblay, Hélène Lauzon, Irène Leboeuf, Janique Beauchamp, Johanne Déry, Karine LeBreton, Louise Patenaude, Luther Germain, Maryse Carignan, Nadia Maddalena, and Robin Gagnon

\section{ABSTRACT}

A research project brought together patient partners, nurse leaders from six clinical settings in Quebec and researchers to develop and test a web technology, the Forum for Knowledge Exchange (FKE), in order to improve discharge planning practices and oncological care transitions. The project led to the creation of a FKE accessible to the oncology sector of the Francophonie. It revealed an innovative strategy of knowledge transfer (KT) based on the FKE and was fed by collaborative work among partners, where the patient partners played a vital role. The results highlighted the importance, for health research, of giving a voice to patient partners in close collaboration with clinicians and researchers so that clinical practices are better adapted to the actual needs of patients and of their relatives.

Key words: nursing, oncology, information and communications technology (ICT), care transitions, discharge planning, participative research, knowledge transfer (KT)

\section{ABOUT THE AUTHORS}

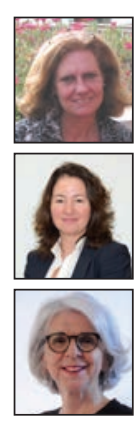

Hélène Lefebvre, RN, PhD, Full professor, Faculty of Nursing, Université de Montréal, C.P. 6128 Succ. Centre-Ville Montreal, QC H3T 3J7; Email: helene.lefebvre@umontreal.ca

Isabelle Brault, RN, PhD, Associate professor, Faculty of Nursing, Université de Montréal, CP. 6128 Succ. Centre-Ville, Montreal, QC H3T 3J7; Email: Isabelle.brault@umontreal.ca

Odette Roy, RN, MSc, MAP, PhD, Founder and researcher at the Maisonneuve-Rosemont Hospital Center of Excellence in Nursing, a position she held until 2015. Associate professor at the Faculty of Nursing, Université de Montréal, CP. 6128 Succ. Centre-Ville, Montreal, QC H3T 3J7; E-mail: oroy.hmr@ssss.gouv.qc.ca

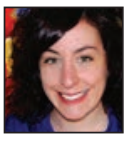

Marie-Josée Levert, PhD, Associate professor, Faculty of Nursing, Université de Montréal, Researcher, Centre for Interdisciplinary Research in Rehabilitation of Greater Montreal (CRIR),

Researcher, Groupe inter-réseaux de recherche sur l'adaptation de la famille et de son environnement (GIRAFE), C.P. 6128, Succ. Centre-Ville, Montréal, QC H3C 3J7; Email : mj.levert@umontreal.ca

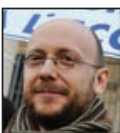

Dan Lecocq, PhD (cand), Maître de conférences \& chercheur, option « sciences et clinique infirmières », École de santé publique, Université libre de Bruxelles; Email : dan.lecocq@ulb.ac.be

Maryse Larrivière, MA Sociology, Project coordinator, Faculty of Nursing, Université de Montréal, C.P. 6128, Succ. Centre-Ville, Montréal, QC H3C 3J7; Email : coordo.riups@gmail.com

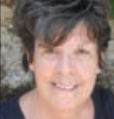

Michelle Proulx, PhD Public Health, Research professional, Faculty of Nursing, Université de Montréal, C.P. 6128, Succ. Centre-Ville, Montréal, QC H3C 3J7; Email : proulxmichelle@videotron.ca

In collaboration with:

André Myre, patient partner; Email: myre.andre@gmail.com

André Néron, patient partner, Email: andre.neron@ulb.ac.be

Caroline Plante, RN, Nursing advisor, Hematology/oncology, rheumatology, immunology and dermatology sectors, Centre hospitalier universitaire SainteJustine, Montreal, QC; Email : caroline.plante.hsj@ssss.gouv.qc.ca
Claudine Tremblay, RN, MScN, Head of the Palliative Care, DIRC and ONP Unit, Oncology Program, Hôpital Maisonneuve-Rosemont, Montreal, QC; Email : claudinetremblay@ssss.gouv.qc.ca

Hélène Lauzon, MBib, Documentalist, Hôpital Maisonneuve-Rosemont, Montreal, QC; Email: informationniste.riups@gmail.com

Irène Leboeuf, RN, MScN, Oncology special care advisor, Centre hospitalier de I'Université de Montréal, Hôpital Saint-Luc du CHUM, Montreal, QC; Email: irene.leboeuf.chum@ssss.gouv.qc.ca

Janique Beauchamp, RN, Clinical nursing advisor, Research and evaluation sector, Professional practices development directorate, Institut universitaire en santé mentale de Montréal, Montreal, QC; Email: jbeauchamp.hlhl@ssss.gouv.qc.ca

Johanne Déry, RN, PhD, Assistant Director of Nursing, Research sector, Centre hospitalier universitaire Sainte-Justine, Montréal, QC; Email: johanne.dery.hsj@ ssss.gouv.qc.ca

Karine LeBreton, RN, MSc, Assistant Chief Nurse, Oncology clientele program, Hôpital Maisonneuve-Rosemont, Montreal, QC; Email: Icompagna.hmr@ssss. gouv.qc.ca

Louise Patenaude, patient partner; Email: lanpat@videotron.ca

Luther Germain, patient partner; Email: Igermain@videotron.ca

Maryse Carignan, RN, Clinical advisor, Nursing directorate, Regional oncology program associate, Centre de santé et de services sociaux de Laval, Laval, QC; Email: mcarignan.csssl@ssss.gouv.qc.ca

Nadia Maddalena, RN, MSc, Senior nursing consultant, Integrated University Health and Social Services Center North of Montreal, Primary care services; Email: N.Maddalena@ssss.gouv.qc.ca

Robin Gagnon, RN, MSc, Oncology nursing program director, Centre de santé et des services sociaux de Lanaudière, Centre administratif, Joliette, QC; Email: robin.gagnon29@gmail.com

Address for correspondence: Hélène Lefebvre, RN, PhD, Full professor, Faculty of Nursing, Université de Montréal, CP. 6128 Succ. Centre-Ville Montreal, QC Canada, H3T3J7; Email: helene.lefebvre@umontreal.ca; Phone: 514-343-2178; Fax: 514-343-2306

DOI:10.5737/23688076282110117 


\section{INTRODUCTION}

$\mathrm{T}$ he improvement of clinical practices with regard to hospital discharge planning and care transitions is at the heart of the concerns of cancer patients, healthcare professionals, decision-makers, and political actors, in order to develop the continuum of care and services in oncology (Institut de la statistique du Québec [ISQ], 2014; Loutfi \& Laflamme, 2006; Ministère de la santé et des services sociaux [MSSS], 2013). Despite numerous efforts put forth to better coordinate care and services for cancer patients, significant shortcomings remain at several levels, specifically in terms of hospital discharge planning, transfers within the same facility, transfers from one facility to another, and transition to the home (ISQ, 2014). The resources available also pose difficulties in terms of support and communication between professionals, at the screening and medical workup stages, during news of the diagnosis, treatment and palliative care (Ganz, Casillas, \& Hahn, 2008; Garderet, Olivier, Najman, \& Gorin, 2006; Hewitt \& Simone, 1999; ISQ, 2014; Kantsiper et al., 2009). These problems are cause for concern given the high number of transitions and discharge plans cancer patients (inpatient and outpatient) experience during the care process (Burge, Lawson, \& Critchley, 2005) and the impact they can have on health and well-being (Comité consultatif concernant les hospitalisations évitables, 2011; Davidson, Moore, MacMillan, \& Wiens, 2004; Davies \& Batehup, 2011).

In continuing the efforts of the Quebec cancer control direction/la Direction québécoise de lutte contre le cancer (DQC) (Loutfi \& Laflamme, 2006), various steps of focus were identified in order to consolidate the continuum of care in oncology (prior to the cancer diagnosis and surgery). The MSSQ (2013) recognized the importance of improving the systematization of clinical practices for discharge planning and care transitions, which are important to patients. In this context, the Nursing network, a partner in care/Le Réseau infirmier un partenaire de soins (NNPIC/RIUPS) of the Université de Montréal (UdeM), conducted a collaborative partnership research project: Developing a clinical innovation in oncology: For a better continuum of care and services for cancer patients. This innovation aimed at bringing together oncology nurse leaders and their multidisciplinary clinical team from clinical settings in Greater Montreal, who agreed to combine their expertise with patient partners and researchers to develop and test an interactive web technology, the Forum for Knowledge Exchange (FKE) (Lefebvre et al., 2015). The aim was to improve practices related to hospital discharge planning and care transitions in oncology.

The project, which was based on the Implementation Science Model of Fixsen et al. (2005), consisted of two phases. The first preparatory phase aimed at deploying the FKE infrastructure and its implementation in the multidisciplinary clinical teams to transform practices in discharge planning and oncology care transitions. The second exploratory phase consisted of assessing the impacts of the FKE in terms of: 1) its implementation in the participating clinical settings, 2) the accessibility of information/knowledge and best practices, and 3) the transformation of practices in hospital discharge planning and care transitions in oncology. This article presents the main results produced in the evaluation phase of the project.

\section{FRAMEWORK}

The multi-level implementation science model was chosen to guide our work because it covers different phases of implementation from the preliminary exploration phase to the adoption phase (Fixsen et al., 2005). It also identifies various facilitating factors that ensure the success of an implementation from a longitudinal perspective. The model is divided into five (5) steps: 1) exploration and adoption (e.g., assessing the fit between the needs of the setting targeted by the change and those of the implementation project); 2) program installation (e.g., securing support at the political, financial and human resources levels); 3) initial implementation (e.g., testing the innovation on a small scale); 4) full operation (e.g., all the actors concerned apply the innovation on a large scale); and 5) long-term sustainability of the implementation (e.g., integrating the innovation into the facilities' policies and clinical protocols). For the purposes of this project, only four steps of the model were considered. The model supported both the implementation and the evaluative part of the project.

\section{METHODOLOGY}

This exploratory project used a collaborative research design (Paillé, 1994), enlisting partners with distinct visions and agendas, to take part in a process of reflection and continuous co-construction to develop and implement the FKE in clinical settings. Having partners was aimed at providing support for the transformation of discharge planning practices and oncological care transitions (Sylvain, 2008).

Governance structure. The project was supported by a governance structure at different levels, bringing together members of the UdeM administration and official representatives, professionals and clinical decision-makers from partner facilities, patient partners, and researchers (Figure 1). The research team comprised four researchers, four professionals (i.e., a coordinator, a documentalist, an FKE moderator, a research professional) and one master's student in nursing.

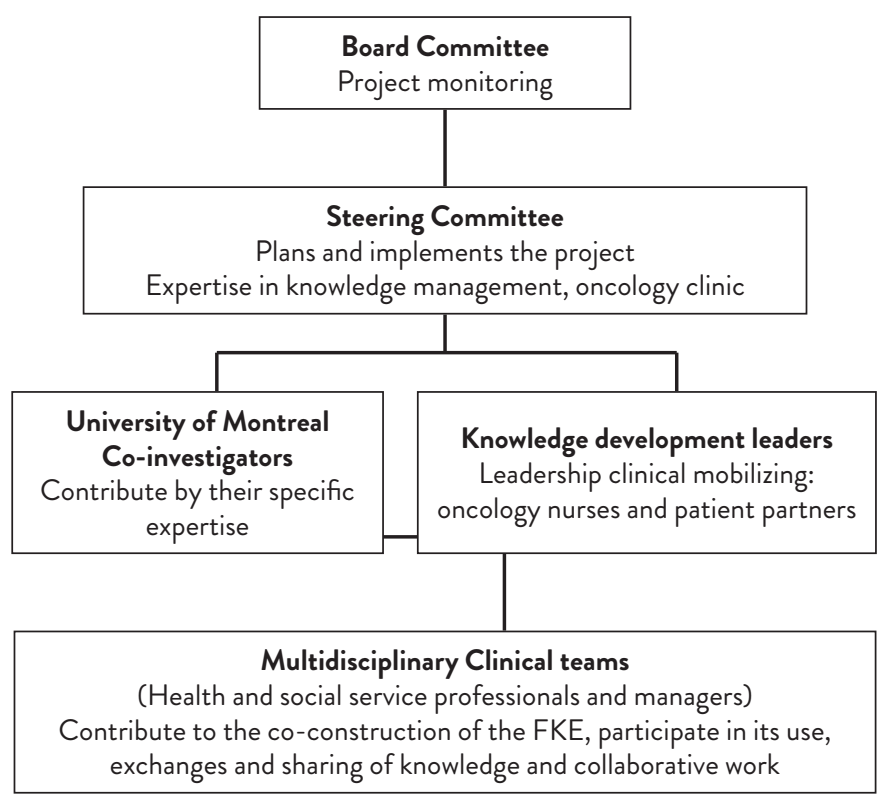

Figure 1: Governance structure 
The project involved six clinical settings, which allowed us to cover the continuum of care (primary, secondary and tertiary), and provided diversified oncological populations (five settings dedicated to the adult clientele and one to the pediatric clientele) and types of cancers treated (e.g., breast cancer, pancreatic, acute myeloid leukemia). Multidisciplinary clinical teams were created in each setting (composed of four to 12 clinicians from different disciplines and managers) who were tasked with participating in the FKE use, as well as in knowledge exchange and collaborative work to improve clinical practices. Each team was supported by a nurse leader, who closely collaborated on different project committees, including the knowledge user group (KUG). This group included the research team, nurse leaders from clinical settings and patient partners. During the development of the FKE, the KUG met on a regular basis to share experiences, solve problems encountered within the clinical settings, plan activities, and develop engagement strategies. A total of eight patient partners were recruited, as part of the project, five of whom were active: two men who were referred by the Direction collaboration et partenariat patient (DCPP) of the Faculty of Medicine of the UdeM, a man referred by a nurse leader from one of the settings, who himself referred a woman who participated with him in a user committee, and a woman referred by a nurse leader of another setting. The other three patient partners did not participate in the project or had little involvement: one had to leave the project to return to school and another never participated because his team did not meet from the time of his recruitment (See implementation challenges). The third patient partner participated very occasionally and remotely (e.g., sending texts to be added in the FKE) due to returning to work.

Data collection and analysis. Data were gathered from written and electronic materials, observation of the KUG meetings, and semi-structured interviews. Twenty-one (21) interviews were conducted with the nurse leaders $(\mathrm{N}=6)$ active throughout the project and one who arrived during the course of the project as a replacement, managers from partner institutions and official representatives $(\mathrm{N}=8)$, and patient partners $(\mathrm{N}=6)$. Approximately 60 minutes long, the interviews were recorded and then transcribed verbatim. The categorization of the data (predetermined and emerging) was carried out by two members of the team (research expertise) and validated by the project's researchers. Syntheses of the data by category were then sent to the KUG partners. These were annotated and then returned to the professionals who, on this basis, drafted the research report. Several versions of the project report were discussed at KUG meetings until a final, satisfactory version was obtained.

The categorization and analyses relied on the Implementation science model developed by Fixsen and collaborators (2005) to place the implementation process within a longitudinal perspective, and on the Consolidated Framework for Implementation Research (CFIR) developed by Damschroder and collaborators (2009) to identify the facilitating factors and obstacles to implementation. The usual criteria for scientific rigour within the constructivist paradigm were respected (Guba \& Lincoln, 1989): credibility (e.g., triangulation of data sources, consensus on data analysis, regular validation), transferability (e.g., detailed description of the study context), and consistency (e.g., indications of any change in the research process). The project was submitted to the Ethics and Research Committees of the relevant institutions. Standards for the free and informed consent of subjects, access to information and confidentiality, prevention of conflicts of interest, and the protection of subjects with respect to harm were ensured.

\section{RESULTS}

Longitudinal approach of the study. The results showed the feasibility of the clinical innovation in terms of its longitudinal implementation approach. The first three stages of the implementation model (Fixsen et al., 2005) were for the most part achieved during the project, significant efforts having been put forth for each of these stages. For example, at stage 1, exploration and adoption of the implementation, agreements with partner institutions were quickly reached, before financing was secured, with regard to the availability of human and material resources (e.g., freeing up work hours, access to material resources). These commitments were renewed when the project obtained financing and started operations. Stage 2, program installation, began when resources in support of the implementation of the FKE were established in clinical settings (e.g., training of multidisciplinary teams, identification of workstations with computers), and when the KUG started its meetings. At this stage, partners co-developed the architecture and the content of the FKE. Stage 3, initial implementation, commenced with the testing of the FKE in clinical settings, followed by registration sessions (account creation) and training for its use as well as technical support provided by the project team. This stage also corresponds with the start of FKE activities in the clinical settings (e.g., webinars, journal clubs, discussion forums). The fourth stage, full operation, began to take shape in spring 2015 within the collaborative work of the KUG, with the aim of developing a tool to support patients and their loved ones during the oncology care process: A tool to support patients during the oncology care process (See also Project outcomes). The objective of the tool is twofold: 1) to address all the questions and concerns patients may have at any given stage in their care or during the transition from one step to another, and 2) help health care and social services professionals (e.g., nurses, doctors, pharmacists, social workers, psychologists), and the organizations for which they work, provide proper support. The tool will be validated and implemented in the participating clinical settings.

Factors facilitating implementation. The project benefitted from a number of conditions that facilitated its implementation. Political support from official representatives (the DQC, the MSSS and the DCPP of the Faculty of Medicine of the UdeM); financial support; emulation effects (positive influence) stemming from collaboration between participating 
settings; and international support (SIRIC: Université Bordeaux, Bergonié Institute, and CHU Bordeaux; BRIO: Professional Research in Cancerology, Bordeaux, France) were established and maintained throughout the duration of the activities. The nurse leaders, who had a lever of influence in their clinical setting (e.g., expertise in oncology and/or position), demonstrated strong leadership skills and were involved during all the activities (e.g., support during project activities in their setting; individual assistance for registration or the use of the FKE; personalized contacts to invite or motivate individuals to participate; sharing the project internally). Managers in the clinical settings contributed, to the best of their capabilities (See Implementation challenges), at the administrative level by freeing up work hours, making material resources available, and granting access to workstations with computers. Some even promoted the project to their institution's senior administration or to members of their professional networks. The researchers' leadership and the support provided by the FKE's moderator (e.g., encouraging exchanges in the discussion forum, providing guidance during collaborative work between partners) and by other professionals in the project team (the coordinator was present in settings to help conduct the webinars) were identified as other factors facilitating engagement. The project teams used various means to encourage, improve or maintain participation (Table 1. Examples of engagement strategies).

The active engagement of patient partners was essential to mobilization, their participation having been constant at different levels of the project. They co-produced video capsules on a variety of themes (e.g., living with cancer or its treatments, role of patient partner); made presentations during two RIUPS study days; participated in Webinars, in setting visits, and in symposiums and conferences; and wrote articles or contributed to discussions in the FKE Forum. They were active at the KUG ( 2 to 4 patients partners per meeting) where they contributed to making decisions on the methodological choices of the project and resolving the difficulties encountered in its development. They also participated in the reflection about strategies for the mobilization of the clinical settings, the co-development of the architecture and content of the FKE, and the planning of the activities grafted to the platform. Even though several managers and nurses leaders who were interviewed sometimes felt unsettled by the patient partner remarks, they nevertheless appreciated their frankness. They

\section{Table 1: Examples of engagement strategies}

- Holding regular on-site meetings of the knowledge user group (KUG).

- Webinars, journal club, discussion forum, news posts shared in weekly newsletters.

- Personalized communications and reminders of activities.

- Creation of an FKE Facebook page and Twitter account to reach young professionals more comfortable with and interested in new technologies.

- Invitation to write texts and to participate in the production of video clips. stressed that the patient partner participation led to a new way of thinking, made them aware of patient expectations and concerns, and opened up new perspectives on the standardized ways care is approached.

"And in any case, I think it is essential to get the patient's point of view. Because sometimes we have the impression, which we hold on to, even in nursing, that we know what's best. Nurses think they know what patients need, but finally, we realize, in any case, from what I observed the little I worked with patients, that sometimes what will actually meet their needs is completely different from what we thought was essential for them (18)."

"Well patient partners, the fact that they were there was a plus for me. We really got both sides of the story, so it wasn't just us professionals sitting there sharing what would be best; we had immediate input. Sometimes, this allowed us to really realign things in the setting (22)."

Implementation challenges. Despite the presence of these winning conditions, two main constraints prevented the FKE from being implemented in clinical settings as desired in the original draft:

1. Nearly one year after the start of activities, five of the six multidisciplinary clinical teams began to face upheavals due to a major reform of the Quebec healthcare system (the pediatric setting has not been affected by the reform; the team's activities were nevertheless considerably slowed down by the challenges experienced in the other participating clinical settings). The reform (Bill 10, an Act to modify the organization and governance of the health and social services network) led to a reshuffling of clinical staff and administrators and to the imposition of important budget constraints throughout healthcare facilities in Quebec. As a result, the initially established designated teams (affected by the reform) had to slow down their activities; the new context gradually led to changes in their composition and, in some cases, complete reconfigurations. Several waves of recruitment of team members had to be carried out, which created disruptions.

"I understand that the timing was all wrong to talk to the teams; there was a change in the management structures where practically all the administrators in the network changed positions, so naturally, when there is instability at the management level, and with the administrators, and when it is through them that you'll work with the teams because they enable contact with the teams, well it complicated things (18)."

2. The outdated computer systems in the facilities were also significant obstacles to engagement, as was the presence of firewalls, which were maintained throughout the project. " ...accessing the Forum, because of the firewalls, was difficult. I think at the IT level, the structure of each centre was a challenge in itself, a challenge for the centre, and when we wanted to access a forum, with all the levels of security to get through, it wasn't easy (8)." 
In addition, difficulties aligning the project's agenda with the new realities in the field were identified by respondents as other potential obstacles to the participation of professionals in the clinical settings. These obstacles included work overload, little leeway for administrators (within the new context of the reform) to free up work hours, and unforeseen delays in the delivery of the FKE because of the complexity of its structure (e.g., a great deal of investment required to choose the FKE's host environment and functionalities, while taking the budget into account). These obstacles, according to some, curbed the enthusiasm felt at the beginning.

Two significant changes in the initial programming of the project were also discussed: the public opening of the FKE (because of the interest it generated in external actors) and the increasing participation of patient partners. According to respondents, some members still active in the designated teams may have felt excluded and no longer considered themselves the main interlocutors. The diversification of the tumour sites covered from one setting to another also appeared, according to some, to have made it more difficult to establish common goals and interests. Difficulties using web technologies, in general, and the platform, in particular (e.g., problems browsing for some), were identified as other potential obstacles to the use of the FKE.

Project outcomes. Despite these constraints, many positive results have been achieved.

An FKE available to the oncology sector. An operational and functional French version of the FKE is now accessible to professionals/administrators and patients/loved ones in the field of oncology. The platform presents several levels of user accounts, secure file management tools, and various functionalities (e.g., a module enabling collaborative work between partners; a module for the dissemination and popularization of knowledge; and a module for adding documentation with URL renewal). A section is specifically dedicated to patients/ loved ones, providing them the opportunity to share resources and links they consider useful. A Facebook page and a Twitter account have been added to the platform in order to reach young professionals who are more comfortable with and interested in new technologies (Facebook, Twitter). The affluence of the platform (visits/use) is steadily increasing. Data gathered for the period from December 17, 2014 to August 30, 2015, indicated there were 155 users initially registered. This rose to 214 from February 1, 2016 to May 31, 2016. As of February 2017, the FKE counted 234 users.

Highlighting an innovative KT strategy. The project revealed an innovative strategy for knowledge exchange and co-construction, as well as an original collaborative work model. The strategy engages active patient partners, nurse leaders and researchers involved in knowledge dissemination and transfer with the support of the FKE and its multiple activities (e.g., seven webinars and journal clubs carried out, nearly 40 questions posed during the discussion forums for a total of 243 interactions, 676 news posts shared in weekly newsletters). The strategy began to develop in the participating clinical settings through the many activities nurse leaders organized of their own initiative that were supported by the platform (Table 2. Examples of initiatives launched).

The benefits of a partnership between patient partners, nurse leaders and researchers. The KT strategy, which is rooted in the day-to-day practice of nurse leaders and fuelled by the comments of patient partners and researchers, has given the project a new meaning. Partners developed new knowledge on difficulties surrounding hospital discharge planning and care transitions in oncology through various common activities (e.g., clinical settings adding internal documents; development of an integrative framework for the trajectory of care in oncology). They were informed and made aware of the multiple challenges associated with care transitions and discharge planning, and of the importance of finding solutions. The project partnership helped break down the silos between institutions and led to the development of a common discourse and to the acknowledgement of diverse philosophies and different ways of administering care.

"Well for me, it was a very positive experience, because I saw what was being done in other environments. It allowed me to develop my knowledge and taught me to be more open to different ways of seeing things, and to interact with patients (22)."

"Co-construction of knowledge is good. Between the different actors, there also seemed to be a close relationship that developed, as is the case in every community of practice once people start trusting each other and feel like they can share. Once they overcome the silo mentality and the culture of competition, and once collaboration occurs (9)."

Thanks to the active participation of patient partners, the difficulties associated with discharge planning and care transitions were progressively examined in a new way. From an initial direction that relied on a professional and organizational viewpoint, the project evolved toward a different representation of care transitions in oncology and discharge planning, from the point of view of cancer patients and their loved ones. This led to a first draft of an accompanying tool, currently under development, that will be available to patients and their relatives.

\section{Table 2: Examples of initiatives launched in clinical settings}

- Downloading of documents of interest by nurse leaders (e.g., on the topic of medically-assisted dying) that were subsequently shared with colleagues.

- Review by colleagues of scientific articles and local documents added by other sites to develop internal tools.

- Personalized invitations to consult the FKE content to prepare papers or write fact sheets on aspects of the of practice to be added to the FKE.

- Promoting the FKE to pivotal nurses from different units, who decided to consult the FKE to prepare communications.

- Replaying a webinar on knowledge transfer (KT) in a clinical setting for clinical consultants from different units.

- A journal club to discuss a published article describing the project protocol followed by a group exploration session of the FKE, leading to a few new registrations. 
The nurse leaders and administrators who were interviewed noted that they were now convinced of the importance of encouraging patient partner participation in future RIUPS projects and in their own projects to co-develop clinical practices. Patient partners also benefitted from their own participation (e.g., they felt valued because of their contribution; they were able to distance themselves from their experience of cancer; and they now have a better grasp of the functioning of the healthcare system).

"So what I understand is that it has helped me a lot to understand how the health system works, and the more I intervene, the more I am able to maintain an emotional distance when things happen that I do not want to live (Patient partner; 10)."

"But surely I found out. It's a world I did not know. At first I did not know at all ... I had not made my career in the world of health, so it was a world I did not know. I found it very interesting, I thought it was a great intellectual challenge for me to do it. Sure, it's very rewarding to think we can contribute something. I found it very stimulating ... it certainly made a lot of sense for me, and I think that whatever the result of this research, I want to continue, to go forward and to participate in other kinds of research (Patient partner; 12)."

The promotion of the FKE. The spread of the FKE, supported and fuelled by its partners and the patient partnership that is central to the project, was very well received in the international Francophonie. A grant was awarded to the SIRIC (Université Bordeaux, Bergonié Institute, and CHU Bordeaux) BRIO (Professional Research in Cancerology, Bordeaux) in France for a breast cancer research project. Moreover, a Belgian RIUPS is in development.

\section{DISCUSSION}

This collaborative research project will be of interest to nurses in healthcare facilities that are committed to improving the continuum of care in oncology. It uncovered the tremendous possibilities that a KT strategy can provide when it relies on an interactive web technology such as the Forum for Knowledge Exchange (FKE). The Forum is supported and fuelled by active partners, united around shared common actions to improve practice with regard to hospital discharge planning and care transitions. A French version of the FKE is now available in the oncology sector for all the actors in healthcare facilities, providing the opportunity for knowledge dissemination and exchange activities, for the transformation of clinical practices, and for continuing professional development in a real-world setting. Bedside clinicians, clinical decision-makers, members of senior administrations, patients and relatives (and others) are now all in direct contact and have the possibility of engaging, synchronously and asynchronously, in a dialogue with others. They all have easy access to knowledge and internal documentation provided by partner institutions (e.g., tools, teaching guides), and also have the possibility of participating in collaborative work virtually. In this respect, the project is aligned with other initiatives in the oncology sector that use interactive web technologies. These initiatives focus on sharing scientific evidence-based knowledge or aim to transform practices by establishing virtual communities of practice, networks or interactive platforms (Bartonova, 2012; Dunn, Eisen, Wayne, \& Crighton, 2004; Farrell, La Porta, Gallagher, Vinson, \& Bernal, 2014; Grau, Grajales, Gene-Badia, Siso, \& de Semir, 2013; Sanchez et al., 2012).

Although the project was supported by a number of factors facilitating the success of the implementation (Damschroder et al., 2009), its partners were confronted with challenges that impeded their efforts to mobilize clinical teams, as desired. In addition to changes in the composition of the designed teams due to the context imposed by the reform of the Quebec health system, the presence of outdated computer systems and firewalls in the sites caused frustration and limited the possibilities of using the FKE and participating in its activities. These difficulties were present throughout the duration. While the scientific community has fully embraced new information and communication technologies, healthcare facilities will have everything to gain in following suit (Ho, Bloch, Gondocz, Elizabeth, \& Wenghofer, 2004) and removing barriers to access (e.g., removing firewalls or increasing bandwidths). A switch to mobile technology (e.g., use of tablets), as well as a greater use of online tools (e.g., web applications, social media) will be essential (Centre de pédagogie appliquée aux sciences de la santé, 2013; Marsan, Paré, \& Wybo, 2012), so that clinicians can benefit from quick and easy access to knowledge.

The difficulties aligning the project's agenda with the new realities of the healthcare facilities and of the clinical environment were also mentioned by some nurse leaders and managers interviewed, as observed or potential obstacles to mobilization (e.g., difficulties in freeing up work hours, difficulties in articulating the project with the needs of the clinical settings). These constraints are identified in the scientific literature as obstacles to the implementation of changes (Damschroder et al., 2009; Fixsen et al., 2005). In order to address these issues in the future, the project's KT strategy will have to remain flexible, given the constraints of healthcare organizations (e.g., limited budget). It will have to promote and support spontaneous initiatives (Cothrel \& Williams, 1999) in the clinical settings and focus on responding to the various needs, preferences and concerns of the registered members of the FKE using multiple channels (Pan \& Leidner, 2003). It will also have to take advantage of the inventiveness of its partners in order to reach the greatest diversity of actors in facilities, regardless of their discipline (Langelier, 2005).

This project will be of interest to anyone seeking a patient partnership participation, which corresponds to a recent trend within healthcare organizations, institutions and universities (Brett et al., 2014; Centre de pédagogie appliquée aux sciences de la santé, 2013; Domecq, Prutsky, Elraiyah et al. 2014; Iedema \& Angell, 2015; South et al., 2016; Woolf et al., 2016). The active participation of patient partners, an innovative element essential to the project, was conclusive. They were a driving force for motivation and mobilization among project nurse leaders and researchers. Their engagement was vital to discussions on care transitions and hospital discharge 
planning. It gave new insight into the object of the project, its methodology and its orientation. This type of contribution is highlighted in the literature (Lavoie-Tremblay et al., 2016; South et al., 2016; Woolf et al., 2016).

\section{CONCLUSION}

The RIUPS implemented an innovative clinical collaborative research project in partnership with multiple institutions and patients partners. To our knowledge, this is one of the first projects of this nature to be conducted, where the findings may prove useful to researchers, clinicians and managers from healthcare organization. The team showed creativity in developing a research strategy that allows all the actors to create a space for the exchange of scientific and experiential knowledge, where everyone is recognized as an expert within this context. GUC meetings continue to be held to further the

\section{REFERENCES}

Bartonova, A. (2012). How can scientists bring research to use: The HENVINET experience. Environmental Health, 11(Suppl. 1), S2.

Brett, J., Stanislas, S., Mockford, C., Herron-Marx, S., ... Suleman, R. (2014). A systematic review of the impact of patient and public involvement on service users, researchers and community. Patient, 7, 387-395.

Burge, F.I., Lawson, B., \& Critchley, P (2005). Transitions in care during the end of life: Changes experienced following enrolment in a comprehensive palliative care program. BMC Palliative Care, $4(3), 1-7$.

Centre de pédagogie appliquée aux sciences de la santé de l’Université de Montréal (CPASS) (2013). Guide d'implantation du partenariat de soins et de services, vers une collaboration optimale entre intervenants et avec le patient. Québec: Université de Montréal, Direction de collaboration et partenariat patient/CPASS.

Centre de santé et de services sociaux de Laval. Ensemble en réseau, pour vaincre le cancer. Plan d'action en cancérologie 2013-2015. Toronto : ministère de la Santé et des Soins de longue durée.

Comité consultatif concernant les hospitalisations évitables (2011). Améliorer le continuum de soins. Toronto : ministère de la Santé et des Soins de longue durée.

Cothrel, J., \& Williams, R.L. (1999). On-line communities: helping them form and grow. Journal of Clinical Oncology, 3(1), 54-60.

Damschroder, L.J., Aron, D.C., Keith, R.E, Kirsh, S.R., ... Lowery, J.C. (2009). Fostering implementation of health services research findings into practice: A consolidated framework for advancing implementation science. Implementation Science, 450.

Davidson, B.J., Moore, K.N., MacMillan, H., \& Wiens, K. (2004). Patient evaluation of a discharge program following a radical prostatectomy, Urologic Nursing, 24(6), 483-489.

Davies, N.J., \& Batehup, L. (2011). Towards a personalized approach to aftercare: A review of cancer follow-up in the UK. Journal of Cancer Education, 5, 142-151.

Domecq, J.P., Prutsky, G., Elraiyah, T., ... Murad, M.H. (2014). Patient engagement in research: A systematic review. BMC Health Serv Res, 14(1), 89.

Dunn, J., Eisen, K., Wayne, J., \& Crighton, F. (2004). The creation of a state and national cancer resource web site for patients and professionals. Oncology Nursing Forum, 31(4), 679-682.

Farrell, M.M., La Porta, M., Gallagher, A., Vinson, C., \& Bernal, S.B. (2014). Research to reality: Moving evidence into development of the accompanying tool in which two patients partners remain very active. The RIUPS believes that the voice of patients partners is essential to health research and must be recognized through close collaboration with clinicians and researchers in order to better adapt clinical practices to the real needs of patients and their relatives.

\section{ACKNOWLEDGEMENTS}

We thank the Canadian Institutes of Health Research (CIHR), The Foundation for Health Research (FRS) for their financial support.

\section{CONFLICT OF INTEREST}

I declare, as well as the other co-authors and collaborators of this manuscript, that we are not subject to any conflict of interest.

practice through an online community of practice. Preventive Chronic Disease, 11, 130272.

Fixsen, D.L., Naoom, S.F., Blase, K.A., Friedman, R.M., \& Wallace, F. (2005). Implementation research: A synthesis of the literature. Tampa Florida: University of South Florida.

Ganz, A., Casillas, J., \& Hahn, E.E. (2008). Ensuring quality care for cancer survivors: Implementing the survivor care plan. Practice Nurse, 24(3), 208-217.

Garderet, L., Olivier, M-P., Najman, A., \& Gorin, N.-C. (2006). L'annonce d'une mauvaise nouvelle. Revue de littérature. Oncologie, 8, HS126-HS131.

Grau, I., Grajales, I.F.J., Gene-Badia, J., Siso, A., \& de Semir, M. (2013). Forum clinic: The shaping of virtual communities to assist patients with chronic diseases. Studies in Health Technology Q Informatics. 183, 271-275.

Guba, E.G., \& Lincoln, Y.S. (1989). Fourth Generation Evaluation. California: Thousand Oaks: SAGE Publications.

Hewitt, M.E., \& Simone, J.V. (1999). Ensuring quality cancer care. Washington, DC, Academy Press, $256 \mathrm{p}$.

Ho, K., Bloch, R., Gondocz, T., Elizabeth, F., \& Wenghofer, E.F. (2004). Technology-enabled knowledge translation: Frameworks to promote research and practice. Journal of Continuing Education in the Health Professions, 24(2), 90-99.

Iedema, R.A., \& Angell, B. (2015). What are patients' care experience priorities? BMJ Qual Saf, 24(5), 356-359.

Institut de la statistique du Québec (2014). Études et documents. La lutte contre le cancer au Québec et en Ontario : une approche centrée sur le patient. Québec : Gouvernement du Québec. ERP 978-2-550-70445-4

Kantsiper, M., McDonald, E.L., Geller, G., Shockney, L., Snyder, C., \& Wolff, A. (2009). Transitioning to breast cancer survivorship: Perspectives of patient, cancer specialists and primary care providers. Journal of General Internal Medicine, 24, 2, 459-466.

Langelier, L. (2005). Travailler, apprendre et collaborer en réseau. Guide de mise en place et d'animation de communautés de pratique intentionnelles. Québec : Centre de recherche et d'innovation dans les organisations (CEFRIO). ISBN pour le dépôt légal : 2-923278-14-3.

Lavoie-Tremblay, M., O’Connor, P., MacGibbon, B., \& Fréchette, J. (2016). The experience of patients engaged in co-designing care processes. The Health Care Manager, 35(4), 284-293. 
Lefebvre, H., Brault, I., Levert, M-.J., Roy, O., ... Larivière, M. (2015). Une innovation pour un meilleur continuum de soin en oncologie : développement et implantation d'un portail web d'échange des savoirs. Revue francophone internationale de recherche infirmière, 1-10. doi:10.1016/j.pec.2008.07.016

Loutfi, A., \& Laflamme, B. (2006). Rapport d'activités 2005-2006. Direction de lutte contre le cancer. Toronto : ministère de la Santé et des Soins de longue durée. ISBN-2-550-48138-6

Marsan, J., Paré, G., \& Wybo, M.D. (2012). Has open source software been institutionalized in organizations or not? Information and Software Technology, 54, 1308-1316.

Ministère de la santé et des services sociaux (MSSS), (2013). Ensemble en réseau, pour vaincre le cancer. Plan d'action en cancérologie 2013-2015.

Paillé, P. (1994). Pour une méthodologie de la complexité en éducation : le cas d'une recherche-action-formation. Revue Canadienne de l'Éducation, 19(3), 215-230.
Pan, S.L., \& Leidner, D.E. 2003). Bridging communities of practice with information technology in pursuit of global knowledge sharing. Journal of Strategic Information Systems, 12, 71-88.

Sanchez, M.A., Vinson, C.A., La Porta, M., Viswanatah, K., ... Glasgow, R.E. (2012). Evolution of cancer control P.L.A.N.E.T. Application des résultats de la recherche. Cancer 1994, 23, 1205-1212.

South, A., Hanley, B.G., Gafos, M., Cromarty, B., ... Vale, C.L. (2016). Models and impact of patient and public involvement in studies carried out by the Medical Research Council Clinical Trial Unit at University College London: Findings from ten case studies. Trials, 17(376), 1-13. doi:10.1186/s1211-016-1488-9

Sylvain, H. (2008). Le devis constructiviste : une méthodologie de choix en sciences infirmières. L'infirmière clinicienne, 5(1), $11 \mathrm{p}$.

Woolf, S.H., Zimmerman, E., Haley, A., \& Krist, A. (2016). Authentic engagement of patient and communities can transform research, practice, and policy. Health Aff, 35(4), 590-594. 